www.jmscr.igmpublication.org Impact Factor 5.244

Index Copernicus Value: 5.88 ISSN (e)-2347-176x ISSN (p) 2455-0450

crossref DOI: _http://dx.doi.org/10.18535/jmscr/v4i6.52

\author{
Journal Of Medical Science And Clinical Research \\ IGM Publication \\ An official Publication of IGM Publication
}

\title{
Comparison between GFR Values Obtained by CG-formula and DTPA Renography in Different Renal Disorders
}

\author{
Authors \\ Dr V. Sivasubramaniyan ${ }^{1,2}$, Mr Sai Shiv Narayan ${ }^{1,2}$, Prof K. Venkataramaniah ${ }^{2}$ \\ ${ }^{1}$ Sri Sathya Sai Institute of Higher Medical Sciences, Prasanthigram 515134, A.P. India \\ ${ }^{2}$ Sri Sathya Sai Institute of Higher Learning, Prasanthinilayam 515134, A.P. India
}

\begin{abstract}
Aim: The present study aims at comparing the glomerular filtration rate (GFR) values obtained by using Cockcroft-Gault (CG) formula and DTPA renography in different renal disorders.

Material and method: This retrospective study consists of 50 patients diagnosed with renal disorders. Out of 50 patients, 25 were males (50\%) in the age range of 7 to 60 with the mean age of $31 \pm 16$ and remaining 25 were females (50\%) in the same age range with the mean age of $34 \pm 14$ refered to us for various renal disorders. Renal scans were done using Siemens dual head gamma camera (E.CAM). The radio pharmaceutical ${ }^{99 m}$ Tc-DTPA was used and injected intravenously. The dose used for the adults was in the range of 3 to $5 \mathrm{mCi}(111$ to $185 \mathrm{MBq}$ ) and the dose used for the children was in the range of 1 to $3 \mathrm{mCi}$ (37 to $111 \mathrm{MBq}$ ), the images were processed by using GFR/Renal differetial processing protocol in icon software.

Result: The mean total GFR by DTPA Gates method was $71.3 \pm 20.8 \mathrm{ml} / \mathrm{min}$ and by the Cockroft Gault (CG) method was $73 \pm 20.2 \mathrm{ml} / \mathrm{min}$. The difference was statistically insignificant indicating an agreement between both the methods in measuring GFR.

Conclusion: The results of the present study suggests that the Gates method used in DTPA renography provides almost equal estimation of GFR in patients with different renal disorders when compared to CG method.
\end{abstract}

Key words: ${ }^{99 m}$ Tc-DTPA Renography, Gamma camera, GFR, CG formula.

\section{Introduction}

Generally GFR is assessed by measuring the concentrations of serum markers, these Serum markers are also called as endogenous substances such as blood urea, nitrogen and serum creatinine (Scr).The other method which is applied for determining the GFR is to measure the clearance of exogenous substances such as inulin, iohexol, chromium-51-ethylenediaminetetraacetic acid (EDTA), technetium-99m labeled diethylene triamine penta acetic acid (Tc-99m DTPA) or I-125 labeled iothalamate ${ }^{[1]}$.There are different methods or equations to determine the GFR such as, Modification of Diet in Renal Disease (MDRD) Study equation, Cockcroft-Gault (CG) formula, Chronic Kidney Disease Epidemiology Collaboration developed recently a new equation (CKD-EPI) for the GFR estimation and the techniques using radioisotopes such as Tc-99mDTPA (DTPA renography), have also been developed for instant assessment of GFR. 
The aim of this study was to compare the GFR value obtained from the CG method and by Tc99m-DTPA renography which uses Gate's equation for the evaluation of the GFR and to corroborate the dependibility of the DTPA renography. This equations are based on the linear relationship of the renal uptake of Tc-99m-DTPA in the Gates and serum creatinine in the $\mathrm{CG}$.

\section{CG equation}

Cockcroft-Gault (CG) equation is named after the scientists who first published the formula, it is most commonly used as a method of estimating GFR in $\mathrm{ml} / \mathrm{min}$ (eventhough it was developed as a method of determining creatinine clearance) from knowledge of serum creatinine, age and weight. This formula expects patient weight to be measured in kilograms $(\mathrm{Kg})$, patient age and Serum-creatinine (Scr) value to be measured in $\mathrm{mg} / \mathrm{dL}$. This equation is helpful because the calculations are simple and can often be performed without the aid of a calculator.

$$
\operatorname{GFR}\left(\frac{m l}{\min }\right)=\frac{(140-\text { Age }) X(\text { Weight })}{(S C r X 72)}
$$

\section{Gates method}

The renal software utilizes gate's formula for the calculation of the GFR. The parameters like height of the patient (in $\mathrm{cm}$ ), weight (in $\mathrm{Kg}$ ) and the age (in years) are given as input according to the program.

Total renal uptake $(\%)=$

$$
\frac{\left[\frac{\mathrm{R}-\mathrm{RB}}{\mathrm{e}^{-\mu \mathrm{x}}}+\frac{\mathrm{L}-\mathrm{LB}}{\mathrm{e}^{-\mu \mathrm{x}}}\right]}{\text { (Preinjection - Postinjection counts) }}
$$

where, $\mathrm{R}=$ right kidney counts, $\mathrm{RB}=$ right kidney background counts, $\mathrm{L}=$ left kidney counts, $\mathrm{LB}=$ left kidney background counts and $\mu=$ linear attenuation co-efficient of ${ }^{99 \mathrm{~m}} \mathrm{Tc}$ in soft tissue which is equal to 0.153 and $x$ is kidney depth given by the equations below which are also known as Tonnesen equations ${ }^{[2]}$.

Depth of right kidney $=13.3 \cdot y+0.7$

Depth of leftt kidney $=13.2 \cdot y+0.7$ where,

$\mathrm{y}=\frac{\text { Weight in } \mathrm{kg}}{\text { Height in } \mathrm{cm}}$

The total GFR in $\mathrm{ml} / \mathrm{min}$ is computed as follows ${ }^{[3]}$.

$$
\mathrm{GFR}=\mathrm{RU} \cdot(9.8127)-(6.82519)
$$

From the above mentioned equation, it is evident that the depth of the kidneys is an important factor in the computation of GFR by Gates method.

\section{Materials and methods}

From the DTPA renal scans done between the month of Nov 2013 to Jun 2014, 50 renal scans which were done without the intravenous Lasix introduction were selected for this study of comparing the GFR values obtained from the CG formula and by the DTPA renography in various renal disorders such as Hydronephrosis (HDN), Pyeloplasty, Calculus, Genitourinary Tuberculosis (GUTB) and Poor Functioning Kidney (PFK) or Non Functioning Kidney (NFK).

This retrospective study includes 50 patients. Out of 50 patients, males were $25(50 \%)$ and females were also $25(50 \%)$. Males in the age range of 7 to 60 years with the mean age of $31 \pm 16$ and the females also in the age range of 7 to 60 years with the mean age of $34 \pm 14$ (See tables 1-3).

The group consisted of Pyeloplasty cases in 17 patients (34\%), Calculus in 11 patients $(22 \%)$, Hydronephrosis (HDN) in 12 patients (24\%), and Genitourinary Tuberculosis (GUTB) in 7 patients (14\%) and the Poor Functioning Kidney (PFK) in 3 patients $(6 \%)$.

These Renal scans were done using Siemens computerized dual head gamma camera (E.CAM) equipped with the Low Energy All-Purpose (LEAP) collimator. Tc99m-DTPA was prepared by using a commercially available freeze-dried kit from the Board of Radioisotope Technology (BRIT), Mumbai, India. Generally, the dose used for the adults was in the range of 3 to $5 \mathrm{mCi}$ (111 to 185 $\mathrm{MBq}$ ) and for the children it was in the range of 1 to $3 \mathrm{mCi}$ (37 to $111 \mathrm{MBq}$ ). 
The patients were positioned posteriorly in the supine position using a large field of view scintillation camera such that the kidneys were included in the imaged field. Whereas, the Xiphisternum and the Pubic symphysis were positioned in the upper part and the lower part of the detector or camera respectively. Before the injection of the radiopharmaceutical ${ }^{99 \mathrm{~m}} \mathrm{Tc}-\mathrm{DTPA}$, the preinjection counts were obtained for 60 seconds. After this the radiopharmaceutical was administered intravenously into an anticubetal vein through bolus injection over the gamma camera, the transit of tracer through the kidneys was recorded. Image acquisition was started with the appearance of the aortic line in the display and the data was acquired in frame mode. Initially, images were acquired at a rate of 2 seconds per frame for 60 seconds to assess the renal perfusion followed by 30seconds per frame for 90 frames. Immediately after patient image acquisition, post-injection counts followed by the anticubetal counts were obtained for 60 seconds each. The diuretic renogram protocol was used for the acquisition purpose and was done using $256 \mathrm{x}$ 256 matrix size.

Injected radioactivity was defined as the difference between pre-injection and post-injection counts, measured in counts per second [3*4]. After the completion of the image acquisition the images were processed by using icon software. The RenalTime Activity Curve (TAC) and GFR (according to the Gates' algorithm) were obtained after the processing.

Table 1: Age and gender distribution

\begin{tabular}{|l|l|l|l|}
\hline Parameters & Number & Percentage & $\begin{array}{l}\text { Age range } \\
\text { (Years) }\end{array}$ \\
\hline $\begin{array}{l}\text { Number of } \\
\text { Male patients }\end{array}$ & 25 & $50 \%$ & $7-60$ \\
\hline $\begin{array}{l}\text { Number of } \\
\text { Female } \\
\text { patients }\end{array}$ & 25 & $50 \%$ & $7-60$ \\
\hline $\begin{array}{l}\text { Total number } \\
\text { of patients }\end{array}$ & 50 & $100 \%$ & $7-60$ \\
\hline
\end{tabular}

Table 2: Descriptive statistics for males

\begin{tabular}{|l|l|}
\hline Parameters (For Males) & Mean \pm SD \\
\hline Weight & $50 \pm 13 \mathrm{Kg}$ \\
\hline Age & $31.5 \pm 16 \mathrm{Years}$ \\
\hline Serum creatinine & $1.1 \pm 0.4 \mathrm{mg} / \mathrm{dl}$ \\
\hline
\end{tabular}

Table 3: Descriptive statistics for females

\begin{tabular}{|c|c|}
\hline $\begin{array}{l}\text { Parameters } \quad \text { (For } \\
\text { Females) }\end{array}$ & Mean \pm SD \\
\hline Weight & $47 \pm 11 \mathrm{Kg}$ \\
\hline Age & $34.9 \pm 14$ Years \\
\hline Serum creatinine & $0.99 \pm 0.35 \mathrm{mg} / \mathrm{dl}$ \\
\hline
\end{tabular}

\section{Results}

In our study on 50 patients diagnosed with different renal disorders, the GFR values obtained by Cockcroft-Gault formula and DTPA renography showed no significant differences. The mean total GFR by DTPA Gates method was $71.3 \pm 20.8$ $\mathrm{ml} / \mathrm{min}$ and by the Cockroft Gault (CG) method was $73 \pm 20.2 \mathrm{ml} / \mathrm{min}$.

The statistical analysis such as $\mathrm{p}$ value test and the Pearson Correlation Coefficient for both the methods to check the correlation between the GFR values were also done. The $P$ value was found to be 0.921 between the GFR obtained from CG method and GFR estimated by DTPA renography. But the Pearson Correlation Coefficient ( $r$ ) between the GFR obtained from CG method and GFR estimated by DTPA renography was found to be 0.97 (Figure1, where $\mathrm{x}=\mathrm{GFR}$ from $\mathrm{CG}$ method and $\mathrm{y}=$ GFR from Gates method for all 50 patients).

Table 4: Descriptive statistics for the measurement of GFR

\begin{tabular}{|l|l|l|l|l|}
\hline GFR Mean & SD & $\begin{array}{l}P \\
\text { value }\end{array}$ & r value \\
\hline $\begin{array}{l}\text { From T9m Tc } \\
\text { DTPA scan }\end{array}$ & 71.3 & 20.8 & 0.921 & 0.97 \\
\cline { 1 - 1 } $\begin{array}{l}\text { From CG } \\
\text { Method }\end{array}$ & 73 & 20.2 & & \\
\hline
\end{tabular}




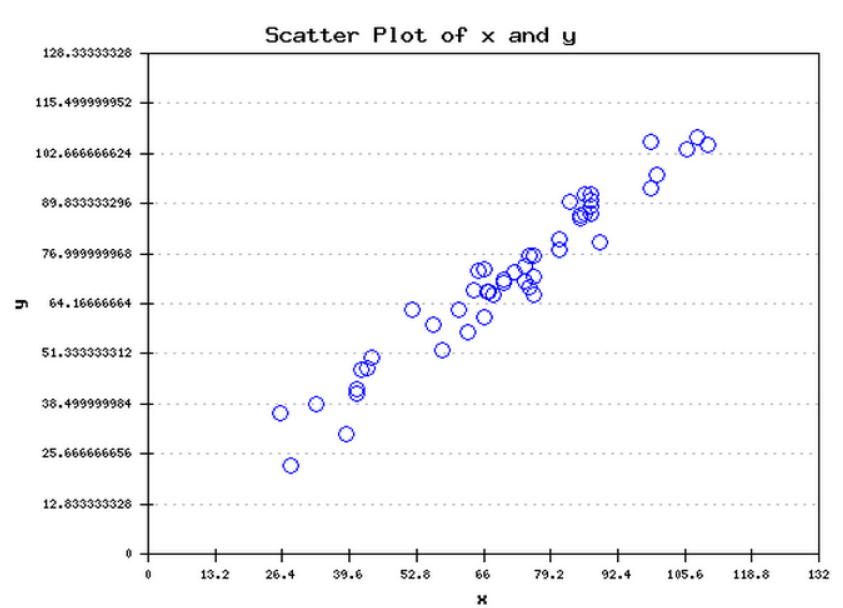

Figure 1: Correlation between the CG method and Gates method.

\section{Discussion}

The $P$ value obtained is more than the significant level i.e. $P>0.05$ and this difference is considered to be not statistically significant. The Pearson Correlation Coefficient (r) value obtained was 0.97, any value between 0.9 and 1.0 means that the GFR obtained from both the methods are highly correlated. And the correlation graph (Graph 1) also shows good linear relationship.

Comparing the various methods by determination of GFR by99mTc DTPA by Gate's renography and predicted creatinine clearance by the Cockroft Gault (CG) equation in 36 patients, Assadi et al. concluded that Gates method is more precise than the CG method ${ }^{[5]}$. Similarly Peterson et al. [6] observed that $99 \mathrm{mTc}$ renography is more accurate than $24 \mathrm{hrs}$ creatinine clearance and is acceptable for clinical use in patients with reduced renal function. He also noted that ${ }^{99 \mathrm{~m}}$ Tc-DTPA renography provides notable information such as quantitative individual renal function and pathophysiological changes of the kidney in renovascular hypertension, hydronephrosis and renal transplant.

The Gates method was considered feasible as it did not involve the cumbersome method of calculation. Nuclear medicine, for many years has had methods for quantitation of renal function, which are simple, accurate and reproducible, do not require urine collection and can be performed on an outpatient basis ${ }^{[1]}$.
The estimation of GFR using Gates method is very simple when compared to the plasma sampling method, which was very cumbersome. In the latter, the timing of sample collection should be accurate. In a busy department, collecting samples and processing them consumes a significant amount of valuable time and dedicated personnel ought to be available throughout the entire procedure ${ }^{[1]}$.

A concern with GFR prediction equations has been the bias from a lack of standard calibration in serum creatinine assays across laboratories ${ }^{[7,8]}$. Presently there is no standard calibration for serum creatinine measurement for laboratories in India much like in the rest of the world. The implication was that a constant calibration bias caused greater inaccuracies in estimated GFR for persons with a normal serum creatinine level than that for persons with an elevated serum creatinine level. ${ }^{[9,10]}$ Other potential sources of measurement error include intra individual variability in serum creatinine, racial and intra individual variability in GFR, and intra-assay variability in creatinine and GFR measurement ${ }^{[11]}$. However, 99mTc-DTPA clearance is relatively less biased and has been accepted as the accurate method for the measurement of GFR in previous

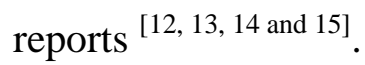

\section{Conclusion}

The results of the present study suggests that the Gates method used in DTPA renography provides almost equal estimation of GFR in patients with different renal disorders when compared to $\mathrm{CG}$ method.

\section{Acknowledgements}

All the three authors feel grateful to Bhaghawan Sri Sathya Sai Baba who is founder Father of the two great Institutions where the present work has been carried out.

\section{References}

1. Julie Hephzibah, Regi Oommen, Nylla Shanthly. Comparison of glomerular filtration rate measured by plasma sample technique, Cockroft Gault method and 
Gates' method in voluntary kidney donors and renal transplant recipients. Indian J Nucl Med. 2013 Jul-Sep; 28(3): 144-151.

2. Glomerular Filtration Rate: Estimation from Fractional Renal Accumulation of $99 \mathrm{mTc}$ DTPA. Review paper.

3. Gopal Sonai Muthu, Sujata Mitra. Improved Quantification of Glomerular Filtration Rate and Differential Renal Function of Ectopic Kidneys in a Dual Head Gamma Camera. Open Journal of Medical Imaging, 2014; 4, 14-227.

4. Yong-il Kim, Seunggyun Ha, Young So, Won Woo Lee, Seok-Soo Byun, and Sang Eun Kim. Improved measurement of the glomerular filtration rate from Tc-99m DTPA scintigraphy in patients following nephrectomy. Eur Radiol. 2014; 24: 413-422.

5. Majid Asadi et al. Comparison of methods for determination of glomerular filtration rate: low and high-dose Tc-99m-DTPA renography, predicted creatinine clearance method, and plasma sample method. In Urol Nephrol 2008; 40:1059-65.

6. Peterson LJ, Petersen JR, Talleruphuus U, Moller TA, Ladefoged SD, Mehlsen J, et al. Glomerular filtration rate estimated from the uptake phase of 99mTc-DTPA renography in chronic renal failure. Nephron Dial Transplant. 1999; 14:1673-8.

7. Séronie-Vivien S, Galteau MM, Carlier MC, Hadj-Aissa A, Hanser AM, Hym B, et al. Impact of standardized calibration on the inter-assay variation of 14 automated assays for the measurement of creatinine in human serum. Clin Chem Lab Med. 2005; 43:122733.

8. Bostom AG, Kronenberg F, Ritz E. Predictive performance of renal function equations for patients with chronic kidney disease and normal serum creatinine levels. J Am Soc Nephrol. 2002; 13:2140-4.

9. Rehling M, Møller ML, Thamdrup B, Lund JO, Trap-Jensen J. Simultaneous measurement of renal clearance and plasma clearance of $99 \mathrm{mTc}$-labelled diethylenetriaminepenta-acetate, 51Cr-labelled ethylenediaminetetra-acetate and inulin in man. Clin Sci (Lond). 1984; 66:613-9.

10. Perrone RD, Steinman TI, Beck GJ, Skibinski CI, Royal HD, Lawlor M, et al. Utility of radioisotopic filtration markers in chronic renal insufficiency: Simultaneous comparison of 125I-iothalamate, $169 \mathrm{Yb}$ DTPA, 99mTc-DTPA, and inulin. The Modification of Diet in Renal Disease Study. Am J Kidney Dis. 1990; 16:224-35.

11. N. Prasad, S. Barai1, S. Gambhir1, D. S. Parasar1, M. Ora1, A. Gupta, R. K. Sharma. Comparison of glomerular filtration rate estimated by plasma clearance method with modification of diet in renal disease prediction equation and Gates method. Indian Journal of Nephrology. March-April, 2012; Vol. 22, No. 2, pp. 103-107.

12. Russell CD, Bischoff PG, Rowell KL, Kontzen F, Lloyd LK, et al. Quality control of Tc-99m DTPA for measurement of glomerular filtration: concise communication. J Nucl Med. 1983; 24: 722-727.

13. Zhao WY, Zeng L, Zhu YH, Wang LM, Zhou MS, et al. A comparison of prediction equations for estimating glomerular filtration rate in Chinese potential living kidney donors. Clin Transplant. 2009; 23: 469-475.

14. Srinivas S, Annigeri RA, Mani MK, Rao BS, Kowdle PC, et al. Estimation of glomerular filtration rate in South Asian healthy adult kidney donors. Nephrology (Carlton). 2008; 13: 440-446.

15. Poge U, Gerhardt T, Stoffel-Wagner B, Sauerbruch T, Woitas RP Validation of the CKD-EPI formula in patients after renal transplantation. Nephrol Dial Transplant. 2011; 26: 4104-4108. 